\title{
Apoptosis induced by overall metabolic stress converges on the Bcl-2 family proteins Noxa and Mcl-1
}

\author{
Felix M. Wensveen $\cdot$ Nuno L. Alves Ingrid A. M. Derks • \\ Kris A. Reedquist $\cdot$ Eric Eldering
}

Published online: 23 April 2011

(C) The Author(s) 2011. This article is published with open access at Springerlink.com

\begin{abstract}
Apoptosis provoked by glucose shortage in dividing $\mathrm{T}$ cells is mediated via the $\mathrm{BH} 3$-only protein Noxa and inhibition of its binding partner Mcl-1. It is unknown how signals from cellular metabolism can affect the balance between Mcl-1 and Noxa and to what extent other Bcl-2 members are involved in this apoptosis cascade. Here, we defined the mechanism underlying apoptosis in relation to various types of metabolic stress. First, we established that the Noxa/Mcl-1 balance is regulated by glucose deprivation as well as by general metabolic stress, via changes in proteasome-mediated degradation of Mcl-1. Second, in contrast with cytokine-deprivation, no transcriptional modulation of Mcl-1, Puma, Bim or Noxa was observed during glucose deprivation. Third, no changes in PKB or GSK3 activity occurred and no clear role for AMPK was detected. Fourth, apoptosis triggered by nutrient deprivation was executed without signs of overt autophagy and independent of ROS production or p38 MAP kinase activity. Lastly, apoptosis under nutrient limitation could also be
\end{abstract}

Felix M. Wensveen and Nuno L. Alves contributed equally to the work.

F. M. Wensveen - N. L. Alves - I. A. M. Derks ·

E. Eldering $(\square)$

Department of Experimental Immunology, Academic Medical

Center, Meibergdreef 9, Room K0-144, 1105 AZ Amsterdam,

The Netherlands

e-mail: e.eldering@amc.uva.nl

Present Address:

N. L. Alves

Cell Activation and Gene Expression Group, Instituto de

Biologia Molecular e Celular, Porto, Portugal

K. A. Reedquist

Department of Clinical Immunology and Rheumatology,

Academic Medical Center, Amsterdam, The Netherlands delayed by knock-down of Bim or overexpression of Bcl-2. In conclusion, Noxa functions in a specific apoptotic pathway that integrates overall nutrient stress, independent from attenuated PI3K/PKB signaling and without clear involvement of autophagy.

Keywords Apoptosis - Glucose $\cdot$ Nutrient deprivation · Noxa

\section{Introduction}

Growth factors and nutrients are essential for lymphocyte survival [1]. Deprivation of these metabolic resources initiates the mitochondrial apoptosis pathway, which is marked by the release of apoptogenic factors from the mitochondrial intermembrane space, such as cytochrome c. Upstream in this cascade, pro-apoptotic Bcl-2 family members Bax and Bak are directly involved in the permeabilization of the mitochondrial outer membrane. Their function is inhibited by protective Bcl-2 members (Bcl-2, Mcl-1, Bcl-XL, A1 and Bcl-w). The pro-apoptotic BH3-only proteins (e.g. Bim, Bid, Noxa, Puma) constitute the third sub-group of this family and are suggested to function as sentinels that integrate distinct extracellular and intracellular insults [2,3].

Dividing lymphocytes, such as antigen-activated $\mathrm{T}$ cells, are highly dependent on nutrients in order to fulfill their metabolic requirements. Triggering of growth factor receptors or of the co-stimulatory molecule $\mathrm{CD} 28$ in conjunction with the $\mathrm{T}$ cell receptor promotes glucose uptake by augmenting the expression of cell surface glucose transporter 1 (Glut1) in a PKB-dependent manner [1, 4]. Previous studies have demonstrated the existence of an apoptotic route coupling nutrient shortage to $\mathrm{Bcl}-2$ family members $[5,6]$. We have demonstrated that during 
TCR-mediated activation, human $\mathrm{T}$ cells upregulate the expression of the BH3-only protein Noxa, and that the balance between Noxa and its pro-survival binding partner Mcl-1 dictates the apoptosis susceptibility of dividing lymphocytes to glucose shortage [7]. Recently, we have shown that the dynamic balance between Noxa and Mcl-1 controls the formation of the effector T cell pool in vivo [8].

Apart from growth factors and glucose, cells require essential anabolic building blocks derived from amino acids. Bcl-2, Bcl-XL and Bim have been shown to play a role in this apoptotic pathway [9-11], but how cellular metabolic stress signals integrate and activate apoptosis executors remains largely unexplored. Various studies have demonstrated a PI3K-dependent transcriptional and posttranslational control of Bcl-2 family members for the induction of apoptosis following growth factor withdrawal. De novo expression of BH3-only proteins Bim and Puma mediated by the forkhead transcription factor $3 a$ (FoxO3a) is a key cellular event caused by attenuation of $\mathrm{PI} 3 \mathrm{~K} / \mathrm{PKB}$ signaling following growth factor deprivation [12, 13]. In addition, PI3K/PKB controls inhibition of glycogen synthase kinase-3 (GSK3) activity, which targets Mcl-1, the antagonist of Puma, Bim and Noxa, for proteasomal degradation following IL-3 or glucose deprivation [14, 15]. Alternatively AMPK, the cellular sensor of energy, has been associated with the control of Mcl-1 protein levels [16]. Thus, this pro-survival molecule has emerged as a common target in apoptosis caused by growth factor and nutrient starvation. However, our understanding of the signaling pathway(s) in response to metabolic stress that converge on Mcl-1 still contains significant gaps.

In this study we questioned how intracellular signaling in response to metabolic stress couples to the proteins Mcl-1 and Noxa. We investigated whether their engagement is restricted to glucose shortage, or may involve other types of nutrient stress. We demonstrate that Noxa is involved in apoptosis caused by general deprivation of nutrients, and that this occurs independently of upstream PI3K components, AMPK and MAP kinases.

\section{Results}

Mcl-1 is targeted to the proteasome during apoptosis provoked by glucose limitation

Both activated $\mathrm{T}$ cells and transformed cells switch their glucose catabolic metabolism from oxidative phosphorylation to glycolysis (the so-called Warburg effect [17]). Cells cultured under low glucose concentrations readily deplete glucose from the medium and undergo apoptosis due to a gradual decline in Mcl-1 levels [7]. The decrease in Mcl-1 might be regulated at the transcriptional level, subsequent to caspase activation after the onset of apoptosis and/or via a post-transcriptional mechanism [16, 18, 19]. First, we investigated whether Mcl-1 or other Bcl-2 family members were transcriptionally regulated in $\mathrm{T}$ lymphoblastic leukemia cells (Jurkat cells, clone J16). The relative mRNA expression of members of the Bcl-2 family, including Mcl-1, Bim and Noxa, as detected by RT-MLPA [20], did not change significantly despite apoptosis induction. In contrast, levels of survivin, a gene regulated in a cell cycle-dependent manner [21], decreased concomitantly with the reduction in cell division (Fig. 1a and data not shown).

We next investigated whether the decline in Mcl-1 degradation required caspase activation. Using either the pan-caspase inhibitor zVAD or J16 cells transduced with dominant-negative caspase-9, the processing of caspase-3 was prevented following glucose deprivation. Yet, the decline in Mcl-1 protein still occurred under these conditions (Fig. 1b), indicating that this labile protein is subject to post-transcriptional regulation. Recently, Pradelli et al. [16] described that during acute glucose deprivation, Mcl-1 protein turnover is maintained, but its levels are decreased by a translational block of Mcl-1 transcripts via activation of AMPK. To investigate whether Mcl-1 turnover was affected during gradual glucose deprivation, its half-life was compared before or after 3 days of culture in lowglucose conditions. Surprisingly, when translation was blocked using cyclohexamide, Mcl-1 half-life was reduced approximately three fold, whereas the half-life of Noxa was not significantly affected (Fig. 1c). Accordingly, the Noxa/ Mcl-1 ratio increased almost 20 fold on day 3, compared to day 0 . Inhibition of proteasome activity by MG132 induced accumulation of both proteins, as previously shown ([2224] and data not shown).

Proteasome inhibition induces apoptosis in cells from the hematopoietic lineage, at least in part via accumulation of Noxa protein [22-24]. If protesomal degradation of Mcl-1 regulates apoptosis in response to glucose deprivation, then MG132-induced cell death should not be affected by glucose deprivation. In addition, reduction of Noxa levels should provide an equal survival advantage under conditions of high and low glucose. Mock transfected Jurkat cells (Mock) and cells in which Noxa was stably knocked down (N8) [7] were exposed to various doses of MG132 after 3 days of culture in medium with $5 \mathrm{mM}$ glucose, or cultured in fresh medium with $25 \mathrm{mM}$ glucose. As previously shown [7], Noxa ablation provided a survival advantage under conditions of low glucose (data not shown). In addition, N8 cells had a survival advantage after treatment with MG132. However, glucose deprivation had no overt effects on the survival of both Mock and N8 cells (Fig. 1d).

In conclusion, since the effects of proteasome inhibition did not grossly alter the apoptosis rates under glucose 

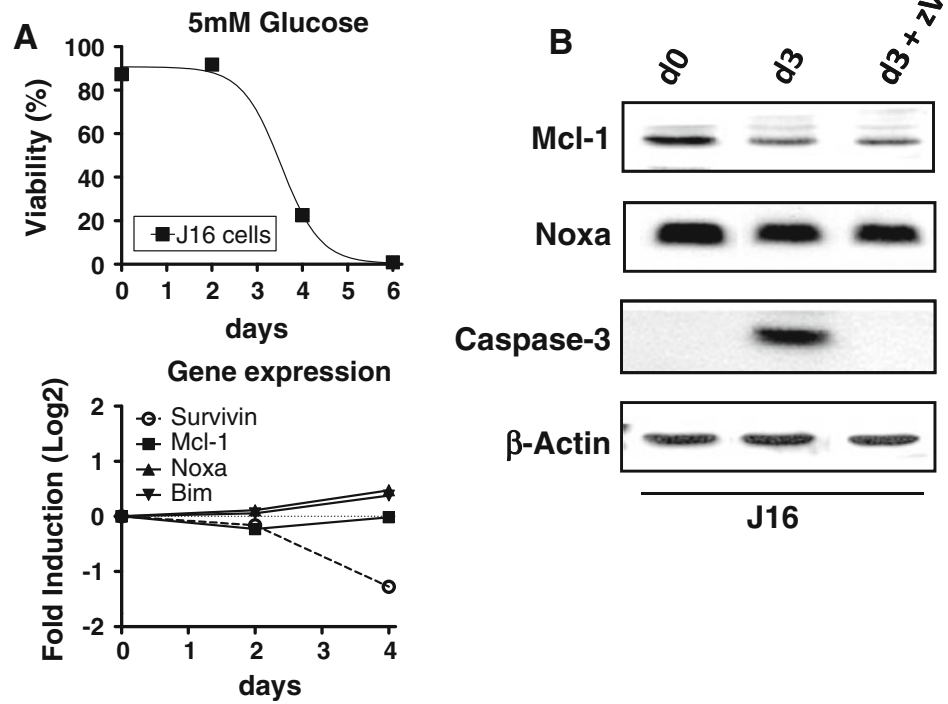
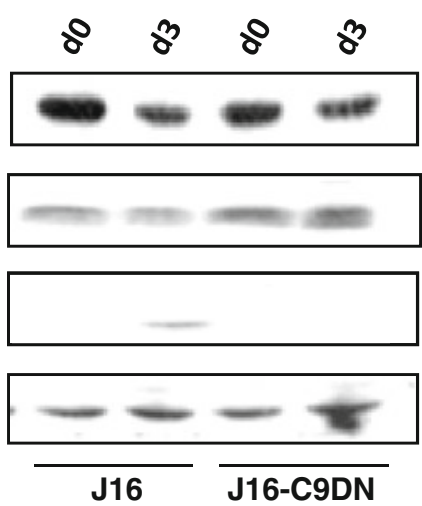

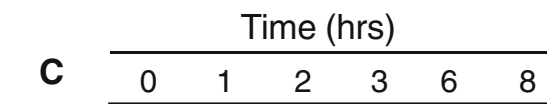

Day 1

Day 3
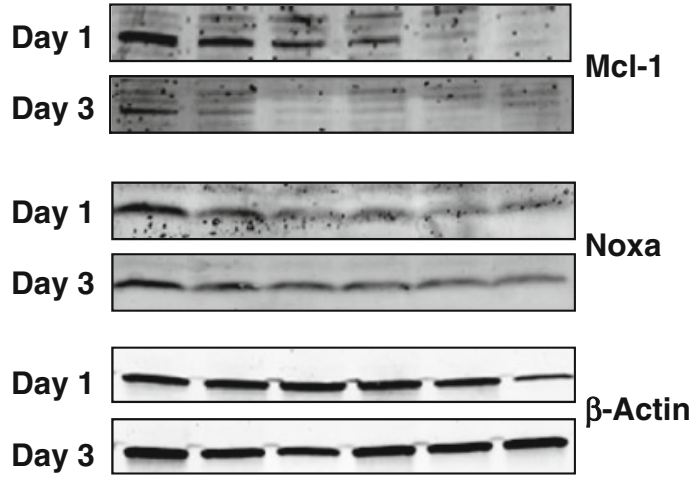

Fig. 1 Mcl-1 is targeted to the proteasome during apoptosis provoked by glucose limitation. J16 cells were cultured under glucose limitation ( $5 \mathrm{mM})$. a At the indicated time points, cell viability was assessed by FACS analyses (top) and mRNA expression of apoptosis genes was measured by RT-MLPA (bottom). The relative expression for each gene was normalized to the value obtained on day 0 . b Caspaseindependent degradation of Mcl-1 during glucose limitation. Cells were analyzed after 0 and 3 days in culture. Left: J16 cells were cultured in the absence or presence of zVAD, supplemented 1 day before lysis. Right: Parental J16 cells in comparison with dominantnegative caspase-9 (J16-C9DN). Protein lysates were analyzed by western blotting and probed for the indicated proteins. c Mcl-1 and

deprivation and/or of Noxa knock-down, no other mechanism than proteasomal degradation of Mcl-1 seems to be the determining factor.

Decrease in Mcl-1 levels following glucose deprivation is independent of AMPK and GSK3 activity

Next, we attempted to identify the intracellular signaling components responsible for Mcl-1 degradation following

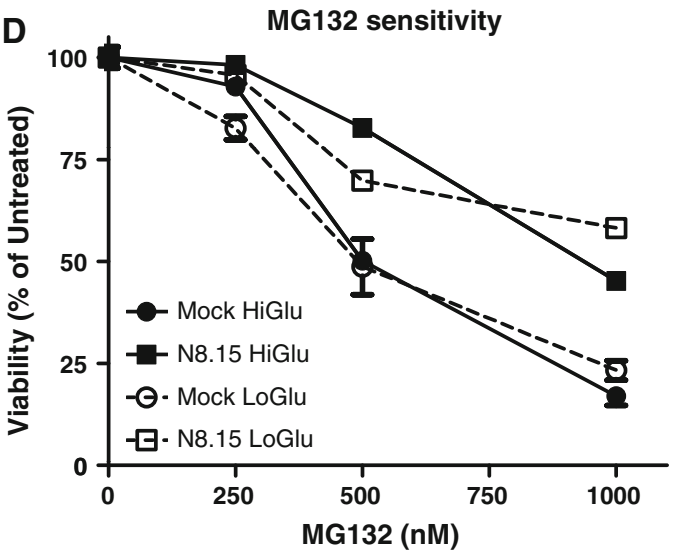

Noxa are targeted to the proteasome during glucose shortage. On day 0 and day 3, J16 cells were treated with cyclohexamide for the indicated time points (hours) and analyzed by western blot. d MG132 sensitivity during glucose deprivation. Mock transduced (Mock) or cells with stably knocked-down Noxa levels (N8.15) were washed in cultured in fresh IMDM at $25 \mathrm{mM}$ glucose (Higlu, closed symbols) or for 3 days in DMEM at $5 \mathrm{mM}$ of glucose (Loglu, open symbols). Then, cells were treated with the indicated concentrations of the proteasomal inhibitor MG132 and viability was measured $24 \mathrm{~h}$ later by mitotracker staining. Results shown are the averaged results ( \pm SEM; note that the error bar is smaller than the symbol) of triplicate measurements performed at least twice

glucose deprivation. AMPK is critical for sensing energy levels (ATP/ADP/AMP ratios) [25]. Since limiting glucose concentrations will negatively influence energy metabolism, AMPK is a candidate to be involved in this process.

First, we measured ATP levels in relation to apoptosis when Jurkat cells were cultured under low starting concentrations of glucose $(5 \mathrm{mM})$. After 2 days in culture, ATP levels were decreased equally in Mock and N8 cells (Fig. 2b). N8 cells retained slightly higher ATP levels after 3 days in 
culture, most likely due to increased cell survival and persistent ATP production. Surprisingly, no differences in AMPK phosphorylation were observed in either Mock or N8 cells after 2 days of culture under limiting glucose concentrations. Instead, a consistent decrease in activated AMPK occurred after several days (Fig. 2c). These data indicate that degradation of Mcl-1 is not associated with AMPK activation.

It has been shown that during glucose deprivation, attenuated PI3K/PKB signals activate GSK3 $\beta$, which targets Mcl-1 to the proteasome [14, 15]. In Jurkat cells, neither PKB or GSK3 $\beta$ seemed to function as potential upstream regulators in this process, as neither the activity of PKB nor the repressive phosphorylation of GSK3 was diminished (Fig. 2d). This was observed in both control cells and cells with reduced Noxa levels, and thus also excluded possible feed-back loops triggered upon apoptosis. Accordingly, we found no difference in apoptosis sensitivity of these cells to inhibition of PKB with Ly294002 or Wortmannin (data not shown).

Since Jurkat cells have excessive PKB activity due to PTEN deletion, we also investigated Mcl-1 degradation in the IL-3-dependent cell line TF-1 under similar conditions as described above. A strong link between cytokine deprivation, GSK3 activity and Mcl-1 stability has been demonstrated [14] and was therefore compared with glucose-deprivation mediated cell death. TF-1 cells rapidly died following IL-3 deprivation, which could be largely prevented by the GSK3 inhibitor SB216763 (SB). Glucose deprivation also induced apoptosis, but this was not significantly affected by SB (Fig. 2e). Mcl-1 levels decreased during IL-3 and glucose deprivation, which could be reversed by re-addition of IL-3 or glucose respectively. Mcl-1 levels were maintained when SB was added to IL-3 deprived cells, but not to glucosedeprived cells (Fig. 2f). Our data indicate that these processes are mediated via different molecular pathways. Accordingly, whereas IL-3 deprivation resulted in reduced levels of phosphorylated GSK3, which could be reversed by adding IL-3, glucose deprivation did not have an effect on the phosphorylation levels of GSK3 (Fig. 2g). Inhibition of AMPK activity by Compound $\mathrm{C}$ did not reduce apoptosis levels after IL-3 or glucose deprivation (Fig. 2h), demonstrating with a complementary approach that this signaling molecule does not play a major role in our experimental system. In summary, these data indicate that gradual glucose deprivation results in Mcl-1 degradation and apoptosis in an AMPK and GSK3-independent manner.

The Noxa/Mcl-1 axis mediates apoptosis provoked by overall nutrient limitation

In our experimental system, cells are not shifted abruptly from $25 \mathrm{mM}$ to $0 \mathrm{mM}$ glucose as done previously [15, 16,
26]. Instead, cells gradually deplete glucose from the culture medium at a starting concentration of $5 \mathrm{mM}$ glucose, mimicking a more physiological situation of hypoglycemia. Under these conditions, a gradual shift in glucose metabolism occurs, which may lead to different stress responses. To investigate this hypothesis, we determined whether the signals that engage Mcl-1 and Noxa emerged during glycolysis or oxidative phosphorylation. In a competitive outgrowth experiment between WT Jurkat and N8 cells under glucose limiting conditions, pyruvate was supplemented to bypass glycolysis and to provide direct substrates for the citric acid cycle. The addition of pyruvate or glucose delayed apoptosis as detected by a drop in mitochondrial membrane potential (MMP) in both populations in a similar fashion, as assessed by mitotracker staining (Fig. 3a, b).

During metabolic crisis, loss of MMP may represent a reduction in catabolic rate and not necessarily apoptosis. Therefore, we tested whether reduced MMP correlated with another standard means of apoptosis measurement, Annexin $\mathrm{V}^{-} / \mathrm{PI}^{-}$cells on day 1 and 3 . We observed only very minor differences between these two methods of measurements (Fig. 3c). These findings indicate that in our culture system MMP loss is equivalent to 'classical' apoptosis measurement.

Next we analyzed whether changes in Noxa or Mcl-1 (Fig. 3d) correlated with sensitivity of Jurkat cells to disruption of the citric acid cycle with the specific aconitase inhibitor SFA [27]. This inhibitor induced apoptosis after $48 \mathrm{~h}$, suggesting that despite the high dependence of dividing cells on glycolysis [17], the responsible stress signals that trigger apoptosis likely derive from oxidative phosphorylation. In addition, a survival advantage for cells with reduced levels of Noxa was observed. In contrast, cells with low Mcl-1 levels displayed increased sensitivity to SFA (Fig. 3e), indicating that the Noxa/Mcl-1 axis plays a role in apoptosis mediated by inhibition of oxidative phosphorylation.

During prolonged culture under starting conditions of high glucose $(25 \mathrm{mM})$ we observed that $\mathrm{N} 8$ cells have a modest survival advantage. Interestingly, glucose concentrations stayed well above levels considered hypoglycemic in vivo $(<3-5 \mathrm{mM})$ [28], and lactate was produced from the start of the experiment (Fig. 4a). These results suggest that deprivation of other nutrients could also engage the Noxa/Mcl-1 apoptotic axis. To test this, we next cultured cells under conditions of high glucose, but with low levels of anabolic supplements, such as amino acids and vitamins (12.5\% of normal values). Apoptosis occurred with clearly different kinetics compared to complete medium but again N8 cells displayed a survival advantage (Fig. 4b), and the level of Mcl-1 decreased concomitantly with apoptosis induction (Fig. 4c). The 
Fig. 2 Decrease in Mcl-1 levels following glucose deprivation is independent of AMPK and GSK3 activity. a-d Mock transduced (Mock) or cells with stably knocked-down Noxa levels (N8) were cultured under low starting concentrations $(5 \mathrm{mM})$ of glucose. a Viability over time relative to day 0 , assessed by mitotracker positivity. b ATP levels over time (RLU/10e6 cells relative to day 0). c AMPK

phosphorylation. Mock or N8 cells were cultured in medium with $25 \mathrm{mM}$ or $5 \mathrm{mM}$ glucose as starting concentrations. At designated time points protein lysates were analyzed by western blotting for total (T) and phosphorylated (P) AMPK (Thr172). One representative experiment of seven performed is shown (d) PKB and GSK3 phosphorylation. At designated time points protein lysates were analyzed by western blotting for Mcl-1, total (T) and phosphorylated (P) PKB (Thr308) and GSK3 (Ser9). Numbers indicate the percentage of viable cells determined by FACS analysis. e- - TF-1 cells were cultured o/n without IL-3 (-IL3) or 2 days without glucose $(-$ glu $)$ in the presence $(+\mathrm{SB})$ or absence of the GSK3 inhibitor SB216763. e Viability measured by FACS. f Western blot analysis of Mcl-1 levels. g Western blot analysis of total $(-\mathrm{T})$ and phosphorylated (-P) GSK3 levels. h TF-1 cells were cultured $\mathrm{O} / \mathrm{N}$ without IL-3 (-IL-3) or 2 days without glucose $(-\mathrm{glu})$ in the presence (+CC) or absence of the AMPK inhibitor Compound $\mathrm{C}$ and viability was measured by FACS
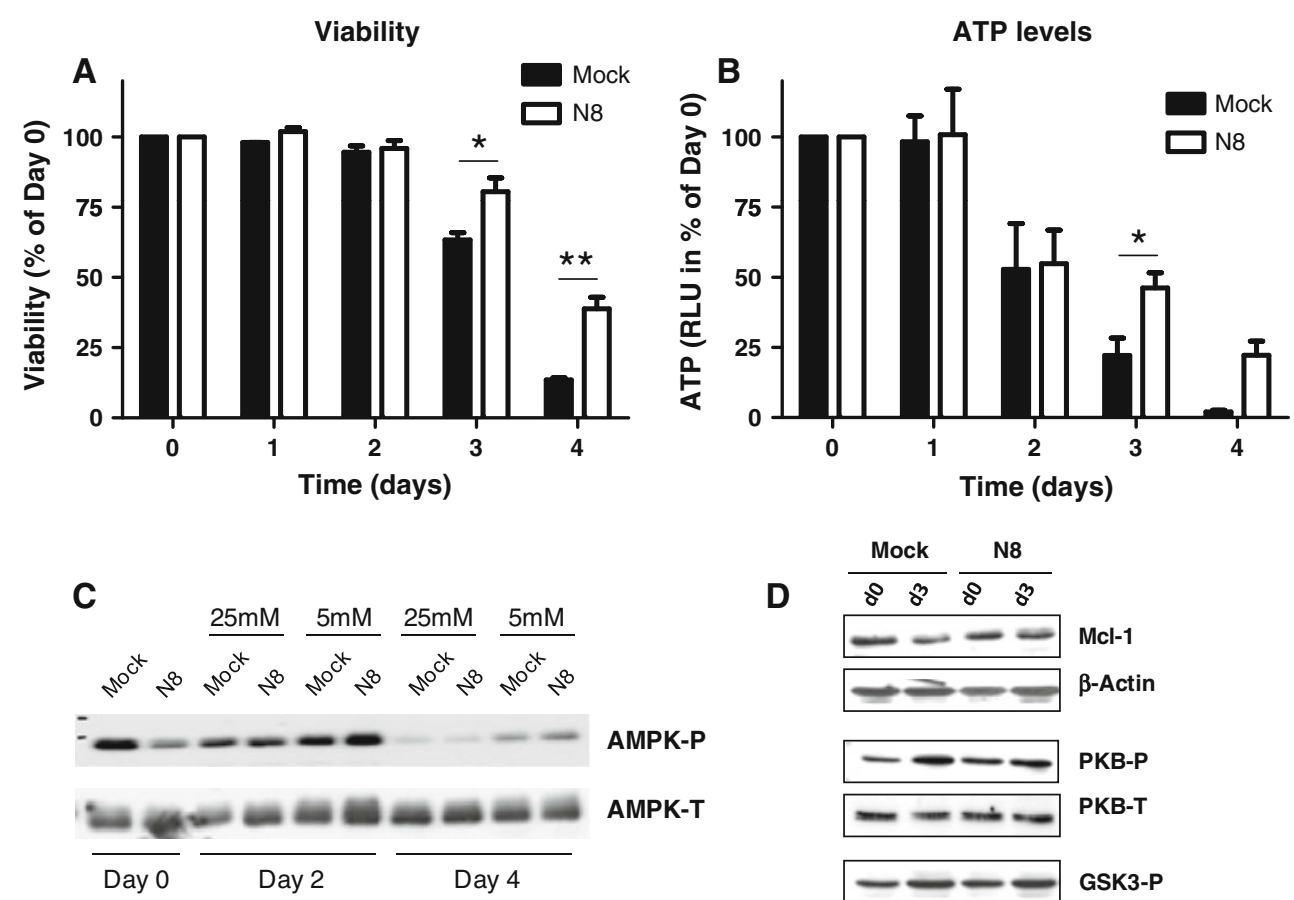

AMPK-P
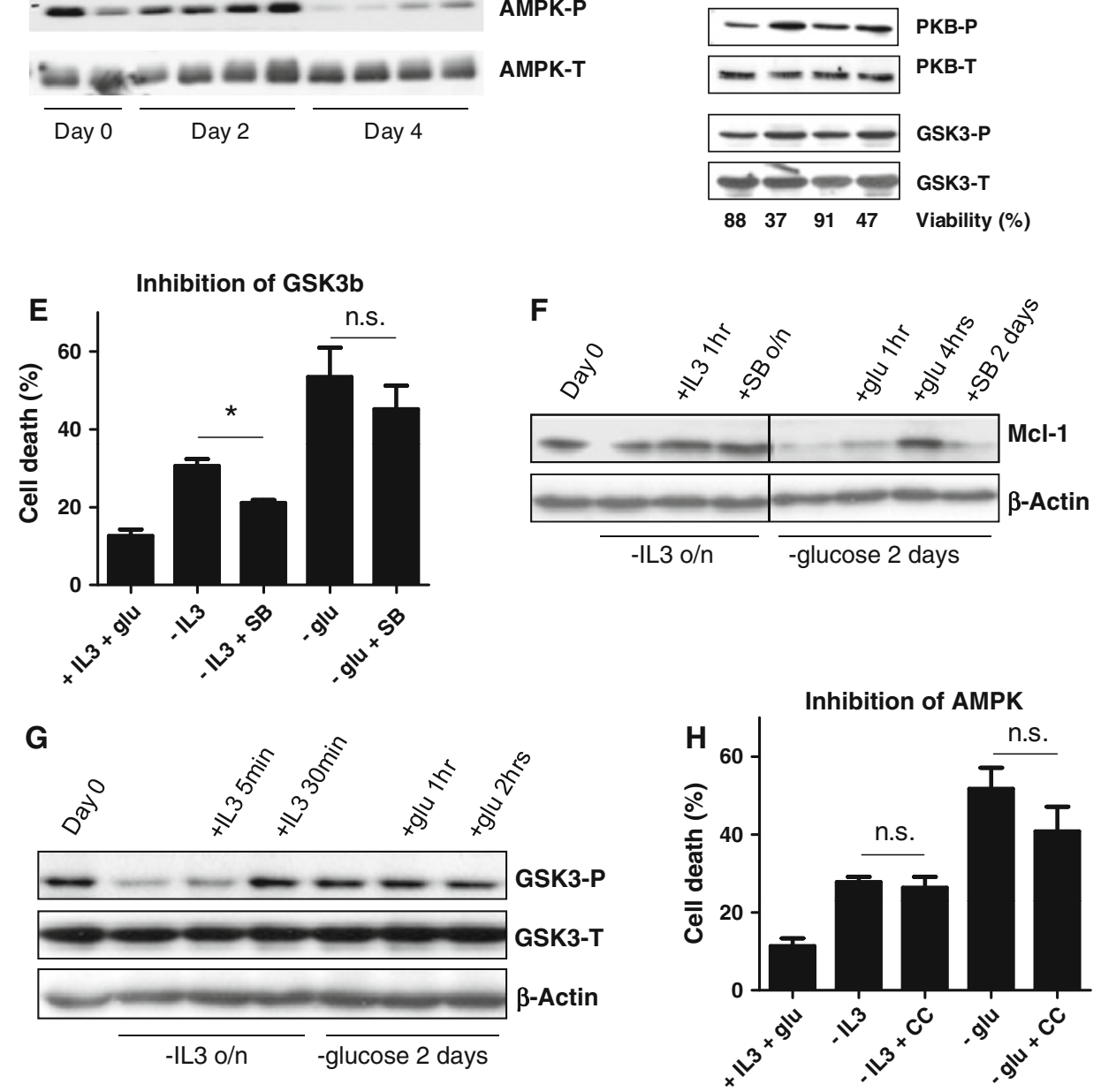

cells ceased dividing, suggesting that inhibition of anabolism triggered apoptosis. To corroborate a link between deprivation of anabolic building blocks and Noxa, the anabolic pentose phosphate pathway was disrupted by the specific inhibitor 6-AN [29]. A clear survival advantage was observed in cells with reduced Noxa levels, whereas cells with low Mcl-1 levels were more sensitive to this compound (Fig. 4d). Together, these data suggest that the Noxa/Mcl-1 axis participates in apoptosis initiated by overall nutrient stress. 

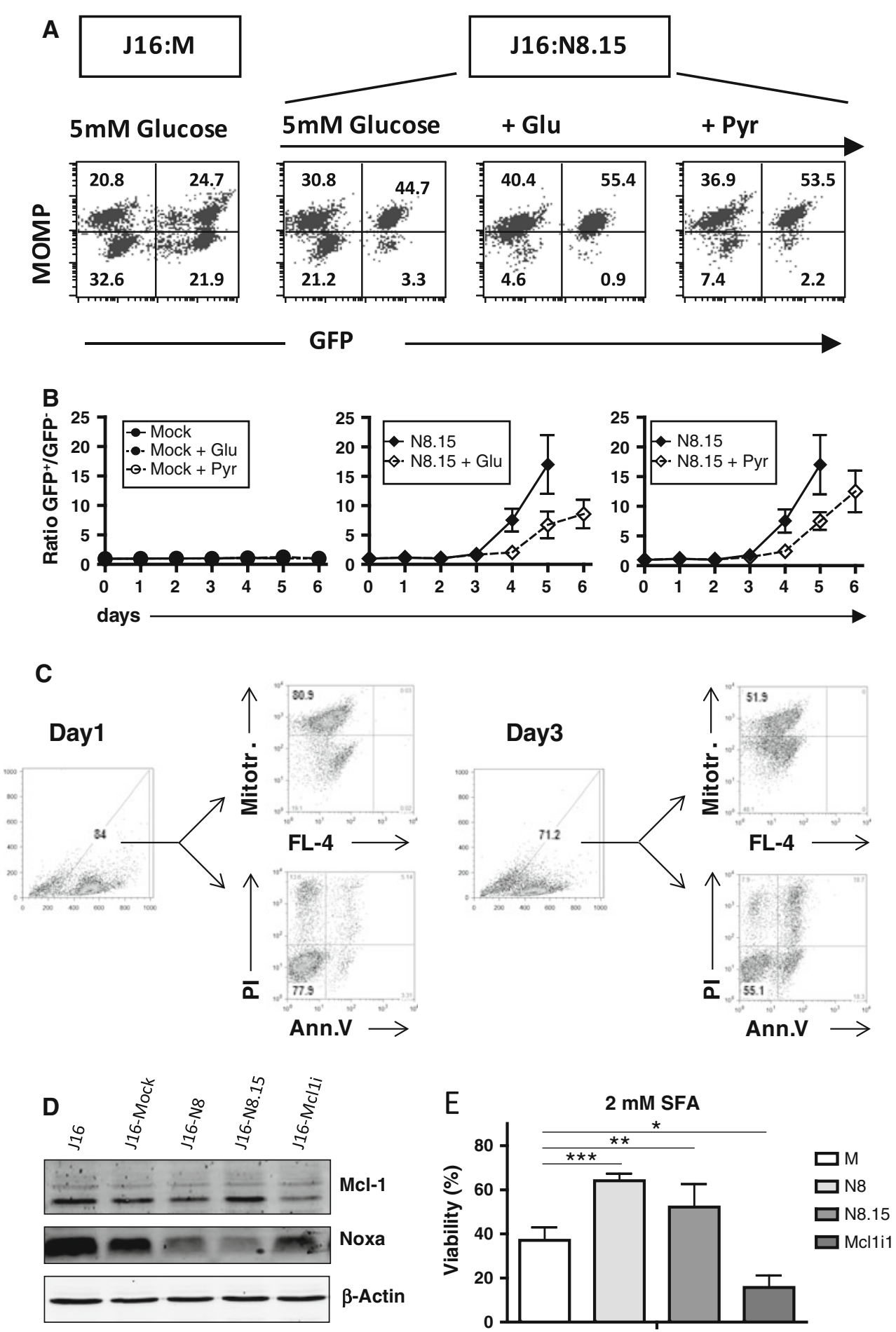

Apoptosis instigated by nutrient shortage occurs in the absence of overt autophagy

Many cell types subjected to starvation undergo autophagy, an evolutionary conserved intracellular degradation process that is instigated via the mTOR complex [30]. Since both

glucose and nutrient starvation can induce autophagy, we investigated whether this molecular pathway may be the underlying mechanism linked to Noxa and Mcl-1. Compared to cell lines that readily induce autophagy during starvation such as the U251 astrocytoma cell line, Jurkat cells appeared less prone to undergo autophagy. This was 
4Fig. 3 Apoptosis under glucose shortage is prevented by addition of pyruvate. Untransduced $\mathrm{J} 16$ cells $\left(\mathrm{GFP}^{-}\right)$were mixed initially at 1:1 ratio with either Mock or N8 clone 15 (N8.15) cells $\left(\mathrm{GFP}^{+}\right)$and cultured in medium supplemented with $5 \mathrm{mM}$ glucose. On day 2, cultures were supplemented with $5 \mathrm{mM}$ glucose (+Glu) or $10 \mathrm{mM}$ Pyruvate $(+\mathrm{Pyr})$. a Shown is a representative experiment on day 3 with cells gated on their FSC/SSC pattern ('viable gate'). Numbers indicate the percentages in the corresponding quadrants. b Survival of control (J16 or Mock) and N8.15 cells. The ratio between mitotrac$\mathrm{ker}^{+}$transduced $\left(\mathrm{GFP}^{+}\right)$and untransduced $\left(\mathrm{GFP}^{-}\right)$cells within the viable gate for the conditions indicated was calculated. Dashed lines with open or closed symbols represent correspondent populations in cultures supplemented with extra $10 \mathrm{mM}$ pyruvate or $5 \mathrm{mM}$ glucose on day 2, respectively. c Cells within the viable gate, cultured under the conditions as described under (a) were quantified by mitotracker staining or AnnexinV/PI staining and measured by FACS on day 1 (left panels) and day 3 (right panels). Representative plots of at least three independent experiments are shown. d Western blot analysis of Mcl-1 and Noxa protein levels in J16 cells, Mock transduced J16 cells, or J16 cells stably expressing the indicated shRNA constructs (see text). e Sensitivity of Jurkat cells to inhibition of the citric acid cycle. The indicated cell lines were cultured in complete medium for $48 \mathrm{~h}$ in the presence of $2 \mathrm{mM}$ Sodium Fluoro-Acetate (SFA). Viability was assessed by mitotracker staining and FACS analysis. Data are averages of at least 3 separate experiments

demonstrated by low levels of lipidized LC3, a well-known autophagy marker [31], when these cells were cultured under low glucose or in the absence of amino acids (Fig. 5a). Inhibition of the mTOR complex by rapamycin did induce conversion of LC3-I into the lipidized LC3-II form in Jurkat cells. High concentrations of rapamycin resulted in cell death, which was not affected by changes in Noxa levels (Fig. 5bi). When cultured under limiting conditions of glucose or amino acids and vitamins, no LC3 lipidation was observed even though $\mathrm{N} 8$ displayed enhanced survival (Fig. 5bii and data not shown). Thus, in Jurkat cells apoptosis induced by nutrient shortage occurs in the absence of overt autophagy.

Noxa/Mcl-1-dependent apoptosis pathway instigated by nutrient shortage is independent of ROS production

Glucose deprivation induces oxidative stress and reactive oxygen species (ROS) and this may activate the MAP kinases p38 and/or JNK [32, 33]. Increased ROS production was indeed observed upon glucose deprivation, which correlated with the induction of apoptosis but this could not be delayed by addition of the ROS-scavenger $\mathrm{N}$-acetylcysteine (Fig. 6a). A slightly increased phosphorylation of p38 at the onset of apoptosis was detected, and phosphorylation of JNK or the pro-survival MAP kinases ERK1/2 was unchanged. Compared to control stimulation with PMA/ionomycin which occurs in minutes, the level of p38 activation was modest after several days of glucose deprivation (Fig. 6b). However, no difference in ROS production or MAP kinase activation between control and N8 cells was observed under these conditions. In addition, Mcl-1 levels were not influenced by external addition of ROS $\left(\mathrm{H}_{2} \mathrm{O}_{2}\right)$, or by intracellular production of ROS following stimulation with CCCP. Also, addition of NAC during glucose deprivation did not prevent Mcl-1 decline (Fig. 6c, d), while it was capable of completely abrogating the pro-apoptotic effects [34] of CCCP (Fig. 6e).

To further investigate the contribution of Mcl-1, Jurkat cells were generated in which Mcl-1, a putative Capsase-3 and -8 target [35], was overexpressed (Fig. 6f). Mcl-1 overexpressing cells displayed decreased sensitivity to death-stimuli such as serum deprivation and CD95-triggering. However, administration of CCCP or $\mathrm{H}_{2} \mathrm{O}_{2}$ did not provide a survival advantage to these cells (Fig. 6g). When Mcl-1 tg cells were cultured under glucose-limiting conditions, they did show a clear survival advantage (Fig. 6h), which was reversed in cells in which Mcl-1 levels were reduced by stable knock-down (Fig. 6i).

Together, these data indicate that the role of the Mcl-1/ Noxa axis upon glucose deprivation does not depend on ROS production or $\mathrm{p} 38$ phosphorylation.

Apoptosis provoked by glucose limitation involves the BH3-only member Bim

The pro-apoptotic effects of BH3-only proteins depend on the Bcl-2 like proteins they are able to antagonize. Noxa binds exclusively to Mcl-1 and to A1/Bfl-1 and is therefore considered a weak inducer of apoptosis. Other BH3-only proteins, like Bim, (t)Bid and Puma bind all Bcl-2 like family members and may directly induce apoptosis $[3,36]$. Hence, apart from Noxa, the apoptosis induced by glucose shortage may involve other BH3-only proteins. As J16 cells express substantial levels of Bim, but not Puma [7] (both under normal or glucose-limiting culture conditions), we targeted the expression of Bim protein with Bim-siRNA [37] (Fig. 7a). Apoptosis induced by known stimuli that require Bim [38-41], such as serum withdrawal and taxol, was decreased in cells with low Bim levels. CCCP treatment, or CD95 triggering, which involves activated Bid [42], was unaffected (Fig. 7b). Subsequently, we performed competitive outgrowth assays under glucose limiting conditions. Cells deficient in Bim displayed a considerable survival advantage and the degree of protection correlated with the level of Bim knock-down (Fig. 7c). As expected, based on current knowledge of interactions among Bcl-2 family members [3], overexpression of Bcl-2 rescued apoptosis under circumstances of limiting glucose concentrations (Fig. 7c). 

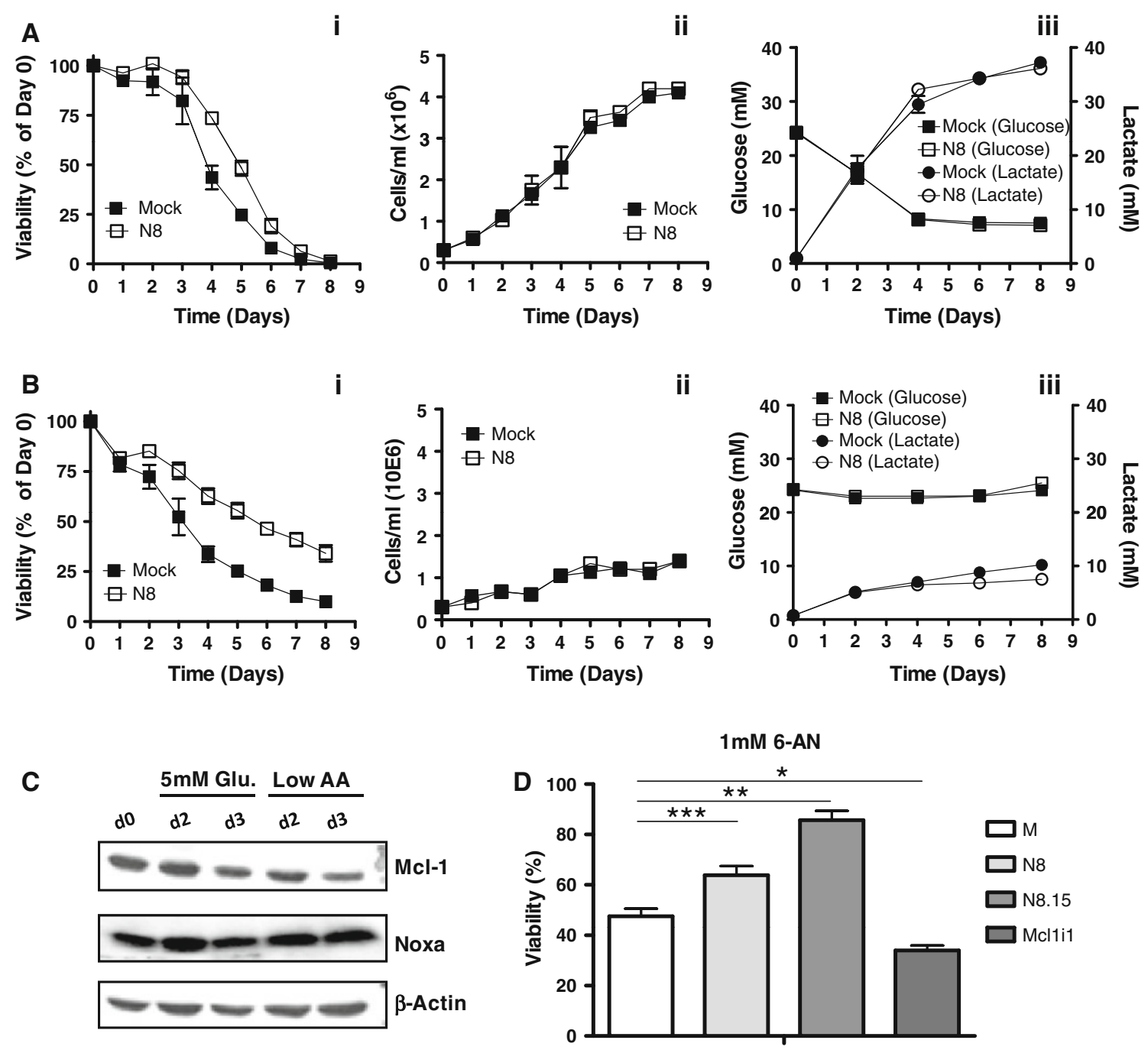

Fig. 4 The Noxa/Mcl-1 axis mediates apoptosis provoked by overall nutrient limitation. a, b Untransduced $\mathrm{J} 16$ cells $\left(\mathrm{GFP}^{-}\right)$were mixed initially at 1:1 ratio with either Mock or N8 J16 cells $\left(\mathrm{GFP}^{+}\right)$and cultured in complete medium or medium with reduced levels of amino acids/vitamins (12.5\% of normal levels in complete medium) (right). (i) Survival (ii) cell density and (iii) glucose and lactate levels in cultures of Mock (closed symbols) and N8 (open symbols) cells. Cell viability was measured based on the percentage of $\mathrm{GFP}^{-}$or $\mathrm{GFP}^{+}$cells found within the total viable population (live and mitotracker positive gating). Glucose consumption (squares) and lactate production (circles) was determined in the supernatants of single cultures, cultured in

\section{Discussion}

The induction of Noxa sensitizes dividing human T cells to apoptosis induced by glucose withdrawal, but not to other apoptotic stimuli such as serum deprivation, CD95 triggering or staurosporin [7]. Here, we further clarify the role of Noxa in the context of metabolic and growth factor deprivation pathways, using Jurkat $\mathrm{T}$ cells and erythroid TF- 1 cells as a model. We find that Noxa has a specific role upon general metabolic stress in an apoptotic response (a) complete medium or in (b) medium with reduced amino acids/ vitamins (right panel). c Untransduced J16 cells were cultured in medium supplemented with $5 \mathrm{mM}$ glucose ( $5 \mathrm{mM}$ glu.) or in medium with reduced levels of amino acids/vitamins (Low AA). At indicated time points, protein lysates were analyzed by western blotting and probed for the indicated proteins. d Sensitivity of Jurkat cells to inhibition of the pentose phosphate pathway. The indicated cell lines were cultured in complete medium for $72 \mathrm{~h}$ in the presence of $1 \mathrm{mM}$ 6-aminonicotinamide (6-AN). Viability was assessed by mitotracker staining and FACS analysis. Data are averages of at least 3 separate experiments

which does not involve upstream components of the PI3K/ PKB/GSK3 path, AMPK or autophagy. Downstream, the function of Noxa converges into an apoptotic signaling cascade involving Mcl-1 and Bim, which are involved in a broad range of apoptotic stress responses.

It is important to note that neither decreased Noxa or Bim levels, nor increased Mcl-1 expression could completely block apoptosis in response to metabolic stress. In accordance with current knowledge on the interaction between Bcl-2 family members [43, 44], functional 


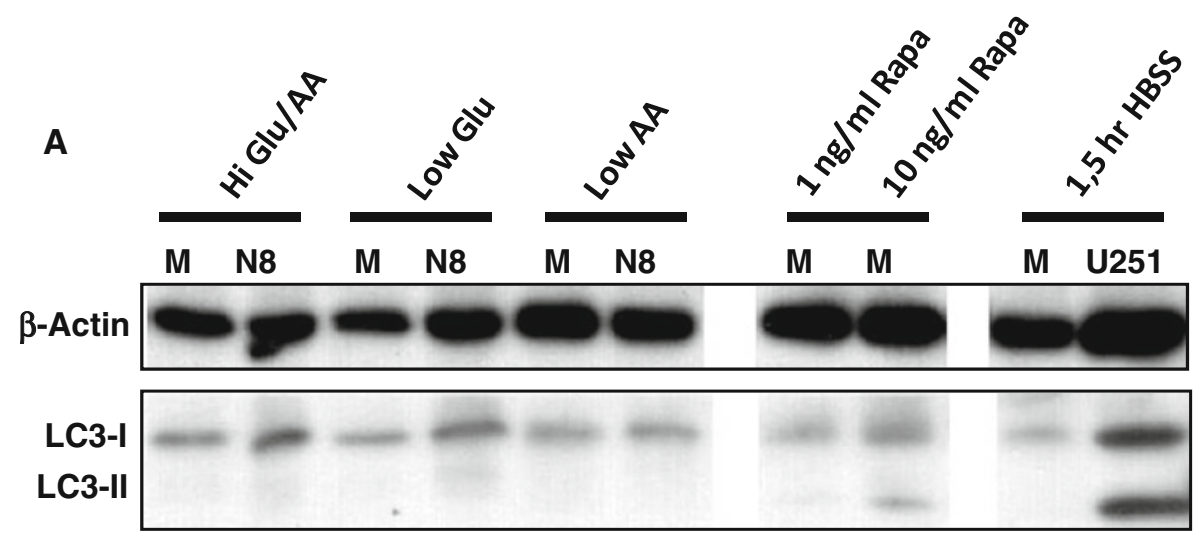

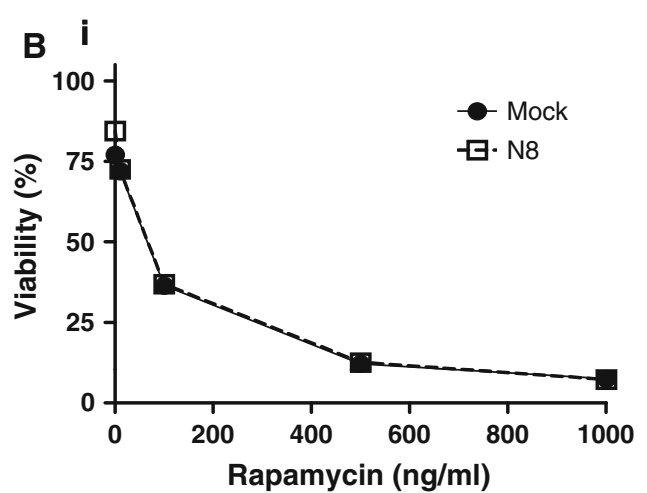

Fig. 5 Metabolic stress does not invoke a significant autophagic response in Jurkat cells. Control (M) or Noxa ${ }^{\text {Low }}$ (N8) J16 cells were cultured for 3 days in complete medium (Hi Glu/AA), medium with $5 \mathrm{mM}$ Glucose (Low Glu) or medium with low amino acids/vitamins (Low AA). a Protein lysates were analyzed for intact and lipidized LC3 (LC3-I and II, resp.). As a positive control for autophagy, J16 control (M) cells and U251 astrocytoma cells were treated with

redundancy between proteins will ultimately always cause apoptosis, except in the case of Bax/Bak double deficiency [45]. The study described here therefore only identifies factors that influence apoptotic-sensitivity to metabolic stress. Since Noxa is considered a 'weak' inducer of apoptosis [43, 44], additional pro-aoptotic molecules, such as Bim will most likely be required to induce cell death. The proteins which are absolutely detrimental are as of yet unclear, but will never involve only a single pro- or antiapoptotic Bcl-2 family member.

Activated T cells markedly shift their catabolism as well as their anabolic requirements. In our study we addressed whether Noxa is involved solely in the apoptotic response to glucose deprivation, or is also engaged by other metabolic stress situations. Reduced levels of Noxa conferred a survival advantage when cells were supplied with pyruvate as energy source, when the citric acid cycle was disrupted or when the pentose phosphate pathway was blocked. In addition, Noxa levels affected the apoptotic response to general nutrient depletion (i.e. amino acids, vitamins). These data indicate that in addition to glucose shortage,

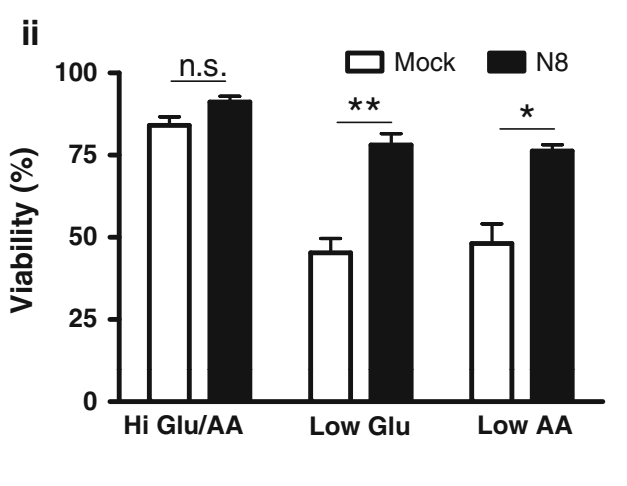

various concentrations of rapamycin (rapa) or cultured for $1,5 \mathrm{~h}$ in HBSS. b Viability of M and N8 cells (i) cultured in complete medium in the presence of increasing concentrations or rapamycin and analyzed after $24 \mathrm{~h}$ or (ii) cultured under conditions of metabolic stress and analyzed after 3 days. Viability was determined based on mitotracker positivity

Noxa regulates apoptosis induced by general metabolic stress.

Mcl-1 is the predominant pro-survival binding partner of Noxa, and its expression is essential for lymphocyte survival [46]. Previously, we described that the decrease in Mcl-1 protein upon nutrient deprivation renders dividing lymphocytes susceptible to apoptosis [7]. Here, we established in more detail that the decline in Mcl-1 level is regulated post-transcriptional via proteasomal degradation and independent from caspase activation. Although Mcl-1 is generally considered as an intrinsically labile protein [47], our findings emphasize that its halflife is subject to regulation depending on the metabolic status of the cell. Since it is reported that the engagement with Noxa in fact controls the half-life of Mcl-1 [48], this implies that signals conveying metabolic stress may indeed converge on Noxa.

Interestingly, a very recent report shows that under homeostatic conditions Cdk5 may phosphorylate Noxa and its phosphorylated form then stimulates aerobic glycolysis. After (acute) glucose deprivation, kinase activity of Cdk5 


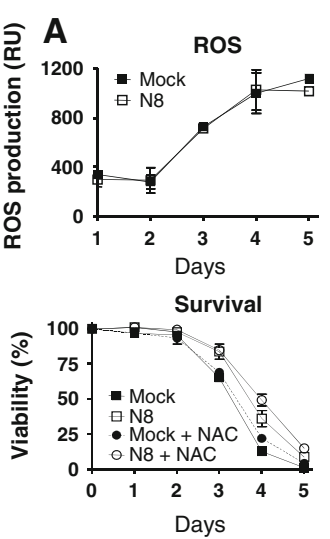

B
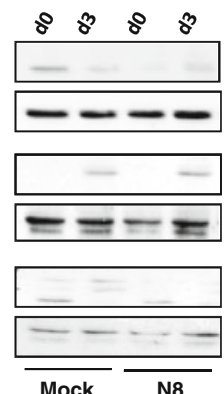

Mock
PMA/ionomycin

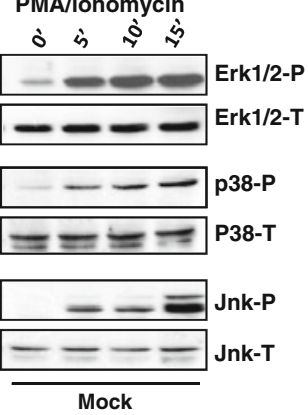

C

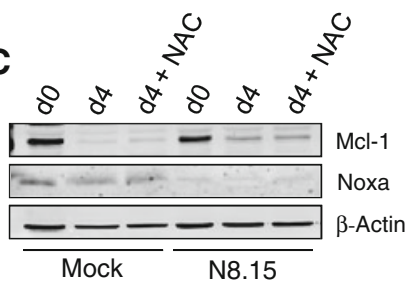

D

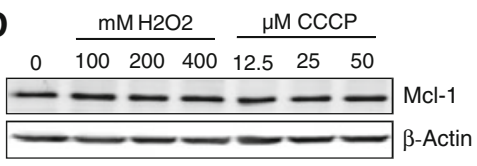

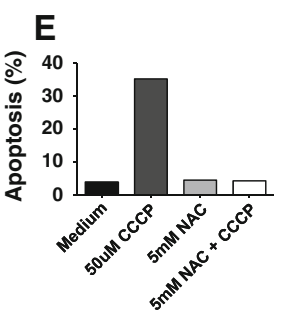

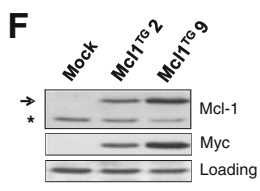

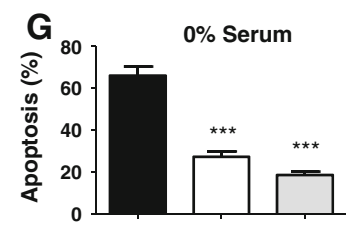

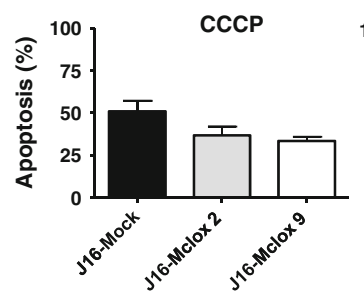

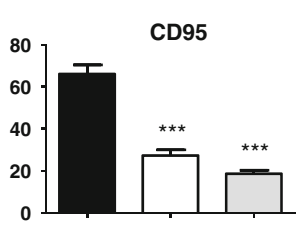

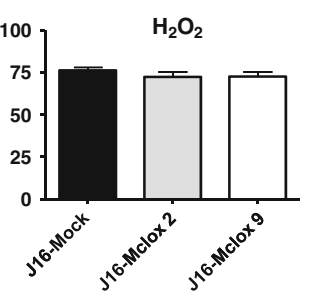

H
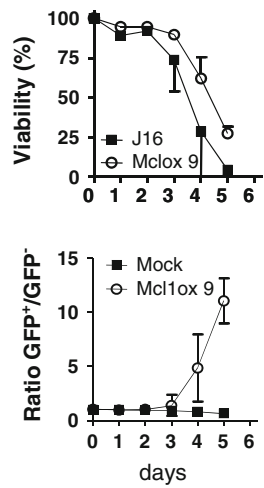

I

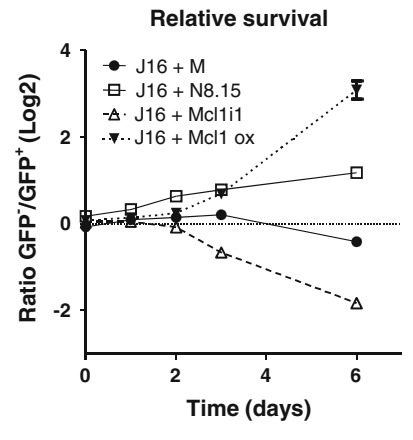

Fig. 6 Noxa/Mcl-1-dependent apoptosis pathway instigated by nutrient shortage occurs is independent of ROS production (a) MAP kinase phosphorylation. Mock and N8 cells were cultured under glucose-limiting conditions. At designated time points protein lysates were analyzed by western blotting for Total (T) and phosphorylated (P) Erk1/2 (Thr202/Tyr204), p38 (Thr180/Tyr182) and JNK 1,2/3 (Thr183/Tyr185). As a positive control, J16 cells were stimulated in parallel with combined PMA $(100 \mathrm{ng} / \mathrm{ml})$ and ionomycin $(1 \mu \mathrm{M})$ for the indicated time points. b-c Mock or N8 cells were cultured under glucose limiting conditions in the presence or absence of the ROS scavenger $\mathrm{N}$-acetylcysteine (NAC). b Cells grown in the absence of NAC were assessed for ROS production by FACS (upper panel). Cells were analyzed daily for viability (lower panel). c Mcl-1 levels were determined by western blot. d Jurkat cells were cultured $\mathrm{o} / \mathrm{n}$ in the presence of the ROS $\mathrm{H}_{2} \mathrm{O}_{2}$ or the mitochondrial uncoupler CCCP and Mcl-1 levels were determined by western blot. e Jurkat cells were cultured in the presence of CCCP, NAC or both. Viability was assessed by PI staining and FACS analysis. f Myc-tagged Mcl-1 overexpression was induced after transduction of cells with a retroviral (LZRS) expression vector. Clear overexpression was achieved after limiting dilution from the bulk population. Mcl-1 and Myc-tag expression in Mock transduced cells and two Mcl-1 overexpressing clones. Arrow indicates transgenic Mcl-1; asterisk indicates endogenous Mcl-1. An aspecific band was used as a loading control. g Mcl-1 Tg cells were treated with the indicated cytotoxic stimuli. Viability was assessed by FACS analysis $24 \mathrm{~h}$ after culture. Data represent mean \pm SD from four to six independent experiments. h Untransduced $\left(\mathrm{GFP}^{-}\right) \mathrm{J} 16$ cells were mixed at a 1:1 ratio with $\mathrm{GFP}^{+}$Mock or Mcl-1 Tg cells and cultured under limiting glucose concentrations. (top) Viability was measured by mitotracker staining. (bottom) The ratio between transduced $\left(\mathrm{GFP}^{+}\right)$and untransduced $\left(\mathrm{GFP}^{-}\right)$cells was calculated between cells in the viable and Mitotracker ${ }^{+}$cell gate. i GFP ${ }^{+}$-transduced (Mock, N8.15, Mcl1 tg or Mcl1i) cells were mixed in a 1:1 ratio with untransduced $\left(\mathrm{GFP}^{-}\right)$ and cultured under low glucose conditions. The ratio between Mitotracker ${ }^{+} \mathrm{GFP}^{+}$and $\mathrm{GFP}^{-}$cells in the viable gate was calculated was diminished, after which unphosphorylated Noxa exerted its pro-apoptotic role [26]. Surprisingly, the phosphorylation state of Noxa did not appear to have a major influence on its interaction with Mcl-1, suggesting that Cdk5-mediated Noxa-phosphorylation does not influence Mcl-1 protein levels. In addition, we did not observe that altered Noxa levels influence metabolic rates (Fig. 4). Differences in the experimental systems applied may underlie these divergent results.
Increased proteasomal targeting of Mcl-1 and subsequent apoptosis was previously also observed upon growth factor deprivation $[14,15]$. This process is mediated by GSK3, which is activated following decreased PKB phosphorylation. However, in different cell lines we observed no decrease in PKB or GSK3 phosphorylation upon glucose deprivation and Mcl-1 decline or apoptosis could not be prevented with GSK3 inhibitors. IL-3 deprivation on the other hand did result in GSK3 mediated 

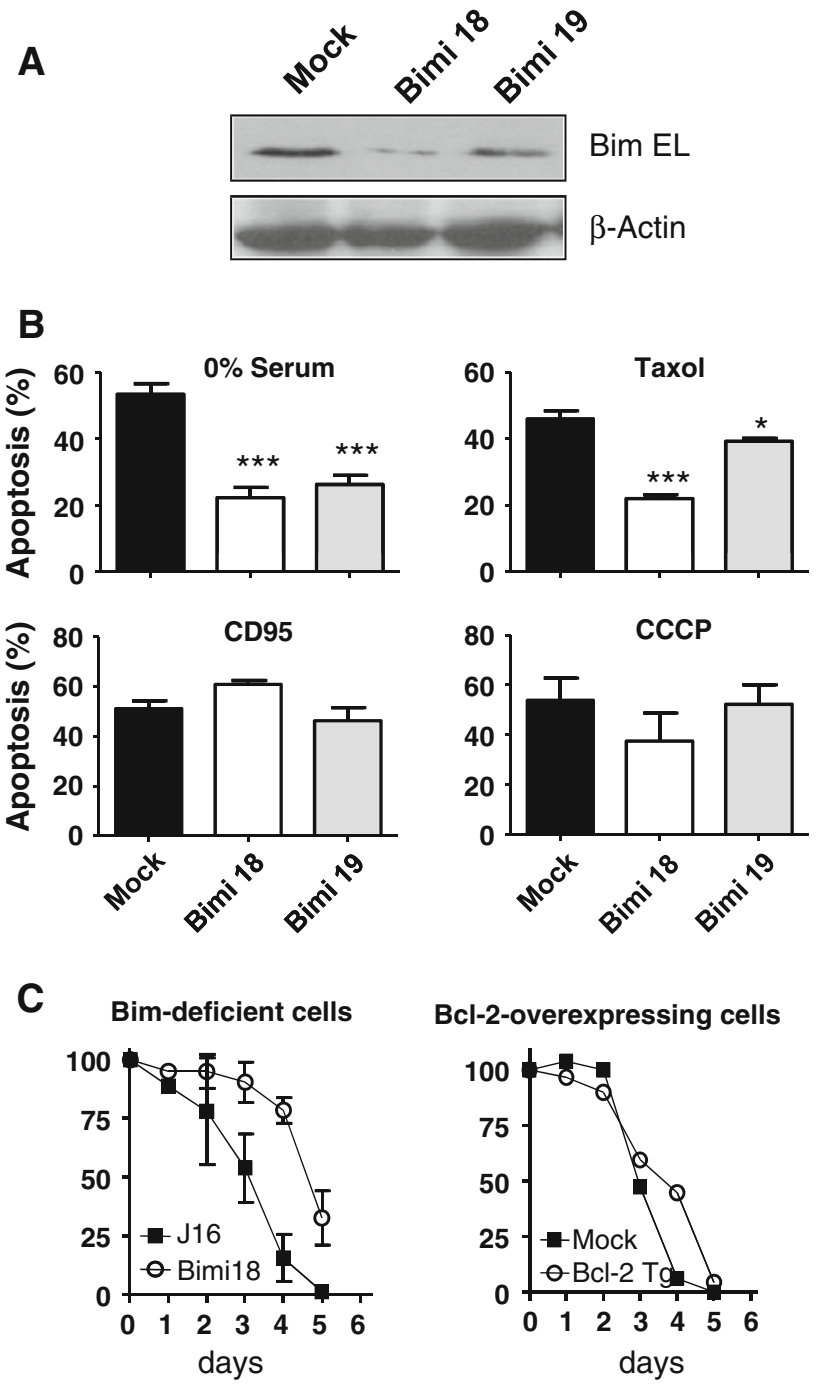

Bim-deficient cells

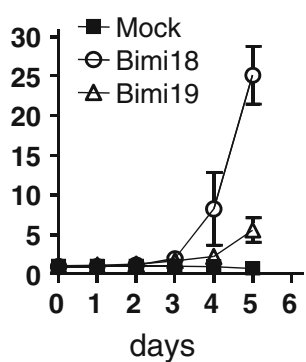

Bcl-2-overexpressing cells

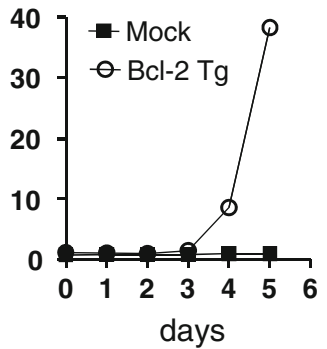

Mcl-1 degradation. This suggests that growth factors and nutrient starvation use two different signaling pathways that converge at the level of Mcl-1 degradation to induce apoptosis.

In seeming contrast with a recent report [16], we observed a gradual decrease in AMPK activity in glucosedeprived Jurkat cells, which correlated with a decrease in Mcl-1 protein. Various observations may account for this apparent discrepancy. First, AMPK is involved in a broad
4Fig. 7 Bim contributes to apoptosis provoked by glucose shortage. a-b Bim knock-down was obtained using Bim shRNA constructs. Clear knock-down was achieved after limiting dilution from the bulk populations. a Bim-EL protein, the prominent Bim isoform in Jurkat was monitored in parental $\mathrm{J} 16$ and 2 Bimi clones by immunoblotting. b Mock and Bimi cells were treated with the indicated cytotoxic stimuli. Viability was assessed by FACS analysis $24 \mathrm{~h}$ after culture. Data represent mean \pm SD from four to six independent experiments. c Untransduced $\left(\mathrm{GFP}^{-}\right) \mathrm{J} 16$ cells were mixed at 1:1 ratio with $\mathrm{GFP}^{+}$ Mock, Bimi (left panels) or Bcl-2 Tg cells (right panels). Cells were cultured under limiting glucose concentrations. At the designated time points, (top) viability was measured by mitotracker staining. (bottom) The ratio between Mitotracker ${ }^{+} \mathrm{GFP}^{+}$and $\mathrm{GFP}^{-}$cells in the viable gate was calculated. Left: Mock (M:J16) (squares), Bimi 18 (Bimi18:J16) (circles) and Bimi19 (Bimi19:J16) (triangles). Right: Mock (J16:M) (squares) and Bcl-2 (Bcl-2:M) (circles). Data represent mean \pm SEM from three experiments

range of metabolic stress responses and intersects with signaling pathways such as PKB and mTOR [25, 49]. Importantly, in primary $\mathrm{T}$ cells and leukemic Jurkat cells, TCR-mediated $\mathrm{Ca}^{2+}$-signaling also activates AMPK, and this occurs independently of increased AMP/ATP ratios [50]. Second, the often used activator of AMPK, 5-aminoimidazole-4-carboxamide riboside (AICAR), induces apoptosis in Jurkat cells which is reportedly independent of AMPK [51]. Third, since we applied a gradual decline of glucose levels, rather than an abrupt loss of glucose or inhibition of glycolysis, as is often applied $[16,50]$, previously unappreciated compensatory mechanisms may occur. These mechanisms may be related to the same general metabolic stress response that mediates cell death after amino acid and vitamin deprivation. Further studies targeting AMPK in various experimental systems may provide more insight into this question.

Likely candidates to regulate metabolic stress responses are the MAPK signaling pathway, autophagy or reactive oxygen species. All of these are related to nutrient starvation-induced cell death and all have been shown to activate mitochondrial apoptosis [49, 52-54]. However, in this study we exclude an overt role for these signaling mediators in Noxa-dependent apoptosis triggered by glucose deprivation. Future studies are required to dissect the molecular connection between sensors of cellular energy and metabolism and apoptosis involving the Noxa/Mcl-1 axis. It appears that primary and leukemic $\mathrm{T}$ cells posses both $\mathrm{TCR} / \mathrm{Ca}^{2+}$ - and ATP/AMP-dependent routes to AMPK activation, which may reflect their intrinsic capacity for rapid cell division and adaptation to metabolic changes.

In conclusion, our data indicate that Noxa sensitizes cells to metabolic stress in a response that targets Mcl-1 for proteasomal degradation, and also involves the concerted action of Bim. 


\section{Materials and methods}

\section{Cell lines}

The J16 clone derived from the human T acute lymphoblastic leukemia cell line Jurkat was used [55]. The Noxadeficient cells J16-N8 and J16-N8.15, and J16 cells transduced with Caspase- 9 dominant-negative were described previously [7, 56]. The J16 cells over-expressing Bcl-2 [57] were kindly provided by Dr. Jannie Borst (NKI, Amsterdam). TF-1 cells were provided by Dr. P Coffer (UU, Utrecht) and maintained with $3 \mu \mathrm{M}$ of human rIL-3 (R\&D research).

\section{Detection of apoptotic cells}

The viability of cells was analyzed by FACS following culture with various death stimuli. Cells were incubated with Mitotracker Orange (200 nM; Molecular Probes) for $30 \mathrm{~min}$ at $37^{\circ} \mathrm{C}$. Alternatively, cells were incubated for $30 \mathrm{~min}$ at $4^{\circ} \mathrm{C}$ with APC-labeled AnnexinV (IQ Products, Groningen, The Netherlands). Just before analysis of the samples by FACS, propidium iodide (PI) (Sigma, St. Louis, MO) was added. Viable cells were defined by their morphological appearance on the FACS ('viable gate') and subsequently as Mitotracker ${ }^{+}$or $\mathrm{AnnexinV}^{-} \mathrm{PI}^{-}$.

\section{Reagents}

Phorbol myristate acetate (PMA $100 \mathrm{ng} / \mathrm{ml}$ ), ionomycin $(1 \mu \mathrm{M})$, N-acetylcysteine $(5 \mathrm{mM})$ and CCCP were purchased from Sigma (St Louis, MO). A panel of different chemical drugs was used to induce apoptosis: LY294002 $(10 \mu \mathrm{M})$ and wortmannin $(50 \mathrm{nM})$ (from Calbiochem., San Diego, CA), rapamycin (Wyeth Laboratories, Philadelphia, PA), velcade $(50 \mathrm{ng} / \mathrm{ml})$ (Janssen-Cilag (Tilburg, The Netherlands), taxol (5 mM) (Sigma) and Fas $10 \mathrm{mAb}(5 \mu \mathrm{g} /$ $\mathrm{ml}$ ) (agonistic antibodies to the CD95 receptor) was a kind gift from Pr of. Dr. L. Aarden (Sanquin, Amsterdam, The Netherlands). Z-VAD (100 $\mu \mathrm{M})$ was obtained from Alexis. Cyclohexamide $(5 \mu \mathrm{g} / \mathrm{ml}), \mathrm{MG} 132(5 \mu \mathrm{M})$ and Compound C (100 nM) were purchased from Calbiochem. The inhibitor SB216763 $(5 \mu \mathrm{M})$ was purchased from Enzo Lifesciences.

Cells were cultured standard in DMEM (Paisley, Scotland, U.K.), with $25 \mathrm{mM}$ glucose and hepes in a humidified incubator at $37^{\circ} \mathrm{C}$ with $5 \% \quad \mathrm{CO}_{2}$. In glucose-limiting experiments, cells were centrifuged and resuspended in DMEM with $5 \mathrm{mM}$ glucose, which was generated by adding of D-Glucose (Merck) to DMEM without glucose (Paisley, Scotland, U.K.). Pyruvate was purchased from Sigma. Amino acid/Vitamin-poor medium was generated by mixing HBSS (BioWhittaker, Verviers, Belgium) with DMEM (25 mM Glucose) in a 8:1 ratio and addition of D-Glucose to a final concentration of $25 \mathrm{mM}$. All cells were cultured in the presence of $10 \%$ FBS (Gibco), Pen/Strep and $50 \mu \mathrm{M}$ Mercaptoethanol (Sigma).

\section{ROS detection}

Cells were transferred to phenolred-free medium (Gibco) and incubated with DHE (14 $\mu \mathrm{M}$; Molecular Probes) for $20 \mathrm{~min}$ at $37^{\circ} \mathrm{C}$. The MFI of cells within the viable gate, caused by DHE oxidation, was measured over 1 min per sample on a FACScalibur.

\section{SDS-PAGE and western blotting}

After washing with ice-cold PBS, cells were either lysed in laemmli sample buffer or NP40 lysis buffer with a protease and phosphatase inhibitor cocktail (Roche). Protein contents were determined by the BCA protein assay (Thermo Scientific, Rockford, IL). Depending on the protein detected, 30-50 $\mu \mathrm{g}$ of protein per lane was separated by SDS-PAGE (13\%) and transferred to nitrocellulose membranes (Hybond-FL, Amersham, Buckinghamshire, UK). Proteins were visualized by staining immuno-blots with anti-Noxa (Biocarta Carlsbad, CA, USA), anti-Mcl-1 (BD Pharmingen), anti-Bim (Stressgen, Canada), anti- $\beta$-actin (Santa Cruz Biotechnology, Inc, Santa Cruz, CA); Anticleaved caspase-3 (Asp175), anti-phospho-PKB(Thr308), anti-phospho-PKB(Thr306), anti-phospho-Erk1/2(Thr202/ Tyr204), anti-Erk1/2, anti-phospho-p38(Thr180/Tyr182), anti-AMPK, anti-phospho-AMPK (Thr172), anti-p38, antiphospo-Jnk1, 2/3 (Thr183/Tyr185), and anti-JNK 1,2/3 were obtained from Cell Signaling Technology; antiphospho-GSK3 $\beta$ (Ser9) and anti-GSK3 $\beta$ were purchased from Santa Cruz. Anti-LC3 (Sanbio BV, The Netherlands) was a kind gift from F.B. Mullauer. Staining was visualised using IRDye 680 or 800 labeled secondary antibodies and an Odyssey Imager (Li-Cor). Quantification of signal was performed using Odyssey 3.0 software.

Reverse transcriptase multiplex ligation-dependent amplification (RT-MLPA) procedure and analysis

Total RNA for Reverse Transcriptase Multiplex Ligationdependent Probe Amplification (RT-MLPA) was extracted using the Trizol isolation method (Invitrogen). mRNA levels were analyzed with the Apoptosis RT-MLPA kit R011 (MRC-Holland, http://www.mlpa.com) according to the manufacturer's instructions. Samples were mixed with ROX500 and run on an ABI 3130 capillary sequencer in Genescan mode. Data was analyzed with GeneMapper 
(Applied Biosystems GmbH; http://www.appliedbiosystems. com) and subsequently with Excell software (Microsoft), as described previously [20].

Glucose, lactate and ATP measurements

Glucose and lactate levels in the supernatants were measured according to standard diagnostic hexokinase and lactate oxidase methods, respectively. Normalized ATPlevels were measured using the ENLITEN ATP Assay System (Promega), according to manufacturer's protocol and measured on a Victor3 (Wallac) multilabel platereader.

\section{Retroviral constructs \& retroviral infection}

To knock-down Bim, we used the pSuper-Bim vector kindly provided by Dr. Andreas Villunger (Innsbruck, Austria), containing the human Bim targeting sequence (referred to as Bimi), described previously [37]. Overexpression of Mcl-1 was accomplished by cloning myc-tagged Mcl-1[58], provided by Prof. J. Borst, in the LZRS-GFP vector. Retroviral particles and transductions were done as described [7]. The efficiency of transduction was estimated by determining the percentage of green fluorescence protein (GFP)-positive cells, 2-3 days later, by flow cytometry. GFP-positive cells were sorted on a FACS sorter (Moflow; Dako-Cytomation, Carpinteria, CA) to $>90 \%$ purity for further experiments. To improve knock-down of Bim or Noxa in J16 cells, a limiting dilution of transduced population was performed according to standard procedures. Resulting clones (N8.15, Bimi18, Bimi19) were selected based on GFP, and further characterized by Western blot.

Open Access This article is distributed under the terms of the Creative Commons Attribution Noncommercial License which permits any noncommercial use, distribution, and reproduction in any medium, provided the original author(s) and source are credited.

\section{References}

1. Frauwirth KA, Thompson CB (2004) Regulation of T lymphocyte metabolism. J Immunol 172:4661-4665

2. Strasser A (2005) The role of BH3-only proteins in the immune system. Nat Rev Immunol 5:189-200

3. Willis SN, Adams JM (2005) Life in the balance: how BH3-only proteins induce apoptosis. Curr Opin Cell Biol 17:617-625

4. Frauwirth KA, Riley JL, Harris MH et al (2002) The CD28 signaling pathway regulates glucose metabolism. Immunity 16:769-777

5. Rathmell JC, Vander Heiden MG, Harris MH, Frauwirth KA, Thompson CB (2000) In the absence of extrinsic signals, nutrient utilization by lymphocytes is insufficient to maintain either cell size or viability. Mol Cell 6:683-692

6. Plas DR, Talapatra S, Edinger AL, Rathmell JC, Thompson CB (2001) Akt and Bcl-xL promote growth factor-independent survival through distinct effects on mitochondrial physiology. J Biol Chem 276:12041-12048

7. Alves NL, Derks IA, Berk E, Spijker R, van Lier RA, Eldering E (2006) The Noxa/Mcl-1 axis regulates susceptibility to apoptosis under glucose limitation in dividing T cells. Immunity 24:703-716

8. Wensveen FM, van Gisbergen KP, Derks IA et al (2010) Apoptosis threshold set by Noxa and Mcl-1 after T cell activation regulates competitive selection of high-affinity clones. Immunity 32:754-765

9. Wei Y, Pattingre S, Sinha S, Bassik M, Levine B (2008) JNK1mediated phosphorylation of $\mathrm{Bcl}-2$ regulates starvation-induced autophagy. Mol Cell 30:678-688

10. Kim YG, Kim JY, Mohan C, Lee GM (2009) Effect of Bcl-xL overexpression on apoptosis and autophagy in recombinant Chinese hamster ovary cells under nutrient-deprived condition. Biotechnol Bioeng 103:757-766

11. Altman BJ, Wofford JA, Zhao Y et al (2009) Autophagy provides nutrients but can lead to Chop-dependent induction of Bim to sensitize growth factor-deprived cells to apoptosis. Mol Biol Cell 20:1180-1191

12. Ekert PG, Jabbour AM, Manoharan A et al (2006) Cell death provoked by loss of Interleukin-3 signalling is independent of Bad, Bim, and PI3 Kinase, but depends in part on Puma. Blood 108:1461-1468

13. You H, Pellegrini M, Tsuchihara K et al (2006) FOXO3adependent regulation of Puma in response to cytokine/growth factor withdrawal. J Exp Med 203:1657-1663

14. Maurer U, Charvet C, Wagman AS, Dejardin E, Green DR (2006) Glycogen synthase kinase-3 regulates mitochondrial outer membrane permeabilization and apoptosis by destabilization of MCL-1. Mol Cell 21:749-760

15. Zhao Y, Altman BJ, Coloff JL et al (2007) Glycogen synthase kinase 3alpha and 3beta mediate a glucose-sensitive antiapoptotic signaling pathway to stabilize Mcl-1. Mol Cell Biol 27:4328-4339

16. Pradelli LA, Beneteau M, Chauvin C et al (2010) Glycolysis inhibition sensitizes tumor cells to death receptors-induced apoptosis by AMP kinase activation leading to Mcl-1 block in translation. Oncogene 29:1641-1652

17. Warburg O, Wind F, Negelein E (1927) The metabolism of tumors in the body. J Gen Physiol 8:519-530

18. Michels J, O'Neill JW, Dallman CL et al (2004) Mcl-1 is required for Akata6 B-lymphoma cell survival and is converted to a cell death molecule by efficient caspase-mediated cleavage. Oncogene 23:4818-4827

19. Lynch JT, Rajendran R, Xenaki G, Berrou I, Demonacos C, Krstic-Demonacos M (2010) The role of glucocorticoid receptor phosphorylation in Mcl-1 and NOXA gene expression. Mol Cancer 9:38

20. Eldering E, Spek CA, Aberson HL et al (2003) Expression profiling via novel multiplex assay allows rapid assessment of gene regulation in defined signalling pathways. Nucleic Acids Res 31:e153

21. Li F, Ambrosini G, Chu EY et al (1998) Control of apoptosis and mitotic spindle checkpoint by survivin. Nature 396:580-584

22. Hallaert DY, Spijker R, Jak M et al (2007) Crosstalk among Bcl-2 family members in B-CLL: seliciclib acts via the Mcl-1/Noxa axis and gradual exhaustion of Bcl-2 protection. Cell Death Differ 14:1958-1967

23. Jullig M, Zhang WV, Ferreira A, Stott NS (2006) MG132 induced apoptosis is associated with p53-independent induction of pro-apoptotic Noxa and transcriptional activity of beta-catenin. Apoptosis 11:627-641

24. Yuan BZ, Chapman J, Reynolds SH (2009) Proteasome inhibitors induce apoptosis in human lung cancer cells through a positive feedback mechanism and the subsequent Mcl-1 protein cleavage. Oncogene 28:3775-3786 
25. Hardie DG, Hawley SA, Scott JW (2006) AMP-activated protein kinase-development of the energy sensor concept. J Physiol 574:7-15

26. Lowman XH, McDonnell MA, Kosloske A et al (2010) The proapoptotic function of Noxa in human leukemia cells is regulated by the kinase Cdk5 and by glucose. Mol Cell 40:823-833

27. Liebecq C, Peters RA (1989) The toxicity of fluoroacetate and the tricarboxylic acid cycle, 1949. Biochim Biophys Acta 1000: 254-269

28. Cryer PE, Axelrod L, Grossman AB et al (2009) Evaluation and management of adult hypoglycemic disorders: an Endocrine Society Clinical Practice Guideline. J Clin Endocrinol Metab 94:709-728

29. Kohler E, Barrach H, Neubert D (1970) Inhibition of NADP dependent oxidoreductases by the 6-aminonicotinamide analogue of NADP. FEBS Lett 6:225-228

30. Yorimitsu T, Klionsky DJ (2005) Autophagy: molecular machinery for self-eating. Cell Death Differ 12(Suppl 2):15421552

31. Kabeya Y, Mizushima N, Ueno T et al (2000) LC3, a mammalian homologue of yeast Apg8p, is localized in autophagosome membranes after processing. EMBO J 19:5720-5728

32. Liu X, Gupta AK, Corry PM, Lee YJ (1997) Hypoglycemiainduced c-Jun phosphorylation is mediated by c-Jun N-terminal kinase 1 and Lyn kinase in drug-resistant human breast carcinoma MCF-7/ADR cells. J Biol Chem 272:11690-11693

33. Lee YJ, Galoforo SS, Berns CM et al (1998) Glucose deprivationinduced cytotoxicity and alterations in mitogen-activated protein kinase activation are mediated by oxidative stress in multidrugresistant human breast carcinoma cells. J Biol Chem 273:52945299

34. Chaudhari AA, Seol JW, Kim SJ et al (2007) Reactive oxygen species regulate Bax translocation and mitochondrial transmembrane potential, a possible mechanism for enhanced TRAILinduced apoptosis by CCCP. Oncol Rep 18:71-76

35. Han J, Goldstein LA, Gastman BR, Rabinowich H (2006) Interrelated roles for Mcl-1 and BIM in regulation of TRAIL-mediated mitochondrial apoptosis. J Biol Chem 281:10153-10163

36. Chen L, Willis SN, Wei A et al (2005) Differential targeting of prosurvival $\mathrm{Bcl}-2$ proteins by their $\mathrm{BH} 3$-only ligands allows complementary apoptotic function. Mol Cell 17:393-403

37. Kuroda J, Puthalakath H, Cragg MS et al (2006) Bim and Bad mediate imatinib-induced killing of Bcr/Abl+ leukemic cells, and resistance due to their loss is overcome by a $\mathrm{BH} 3$ mimetic. Proc Natl Acad Sci USA 103:14907-14912

38. Labi V, Erlacher M, Kiessling S, Villunger A (2006) BH3-only proteins in cell death initiation, malignant disease and anticancer therapy. Cell Death Differ 13:1325-1338

39. Hildeman DA, Zhu Y, Mitchell TC et al (2002) Activated T cell death in vivo mediated by proapoptotic bcl-2 family member bim. Immunity 16:759-767

40. Sunters A, Fernandez de Mattos S, Stahl M et al (2003) FoxO3a transcriptional regulation of Bim controls apoptosis in paclitaxeltreated breast cancer cell lines. J Biol Chem 278:49795-49805

41. Ley R, Balmanno K, Hadfield K, Weston C, Cook SJ (2003) Activation of the ERK1/2 signaling pathway promotes phosphorylation and proteasome-dependent degradation of the BH3-only protein, Bim. J Biol Chem 278:18811-18816

42. Li H, Zhu H, Xu CJ, Yuan J (1998) Cleavage of BID by caspase 8 mediates the mitochondrial damage in the Fas pathway of apoptosis. Cell 94:491-501

43. Kim H, Rafiuddin-Shah M, Tu HC et al (2006) Hierarchical regulation of mitochondrion-dependent apoptosis by BCL-2 subfamilies. Nat Cell Biol 8:1348-1358

44. Willis SN, Fletcher JI, Kaufmann T et al (2007) Apoptosis initiated when $\mathrm{BH} 3$ ligands engage multiple $\mathrm{Bcl}-2$ homologs, not Bax or Bak. Science 315:856-859

45. Lindsten T, Ross AJ, King A et al (2000) The combined functions of proapoptotic Bcl-2 family members bak and bax are essential for normal development of multiple tissues. Mol Cell 6:1389-1399

46. Opferman JT, Letai A, Beard C, Sorcinelli MD, Ong CC, Korsmeyer SJ (2003) Development and maintenance of B and T lymphocytes requires antiapoptotic MCL-1. Nature 426:671-676

47. Opferman JT (2006) Unraveling MCL-1 degradation. Cell Death Differ 13:1260-1262

48. Czabotar PE, Lee EF, van Delft MF et al (2007) Structural insights into the degradation of Mcl-1 induced by $\mathrm{BH} 3$ domains. Proc Natl Acad Sci USA 104:6217-6222

49. Wullschleger S, Loewith R, Hall MN (2006) TOR signaling in growth and metabolism. Cell 124:471-484

50. Tamas P, Hawley SA, Clarke RG et al (2006) Regulation of the energy sensor AMP-activated protein kinase by antigen receptor and $\mathrm{Ca}^{2+}$ in T lymphocytes. J Exp Med 203:1665-1670

51. Lopez JM, Santidrian AF, Campas C, Gil J (2003) 5-Aminoimidazole-4-carboxamide riboside induces apoptosis in Jurkat cells, but the AMP-activated protein kinase is not involved. Biochem J 370:1027-1032

52. Ueda S, Masutani H, Nakamura H, Tanaka T, Ueno M, Yodoi J (2002) Redox control of cell death. Antioxid Redox Signal 4:405-414

53. Shimizu S, Kanaseki T, Mizushima N et al (2004) Role of Bcl-2 family proteins in a non-apoptotic programmed cell death dependent on autophagy genes. Nat Cell Biol 6:1221-1228

54. Shen HM, Liu ZG (2006) JNK signaling pathway is a key modulator in cell death mediated by reactive oxygen and nitrogen species. Free Radic Biol Med 40:928-939

55. Boesen-de Cock JG, Tepper AD, de Vries E, van Blitterswijk WJ, Borst J (1999) Common regulation of apoptosis signaling induced by CD95 and the DNA-damaging stimuli etoposide and gammaradiation downstream from caspase- 8 activation. J Biol Chem 274:14255-14261

56. Werner AB, Tait SW, de Vries E, Eldering E, Borst J (2004) Requirement for aspartate-cleaved bid in apoptosis signaling by DNA-damaging anti-cancer regimens. J Biol Chem 279:2877128780

57. Werner AB, de Vries E, Tait SW, Bontjer I, Borst J (2002) Bcl-2 family member Bfl-1/A1 sequesters truncated bid to inhibit is collaboration with pro-apoptotic Bak or Bax. J Biol Chem 277:22781-22788

58. Inoshita S, Takeda K, Hatai $T$ et al (2002) Phosphorylation and inactivation of myeloid cell leukemia 1 by JNK in response to oxidative stress. J Biol Chem 277:43730-43734 